\title{
A Review of Methods to Increase the Availability of Wind Turbine Generator Systems
}

\author{
Udai Shipurkar, Henk Polinder, and Jan A. Ferreira
}

\begin{abstract}
Availability is an important factor to be considered when designing wind turbine generator systems. The quest for increased availability is based on the following five design approaches - design for component reliability, active control for reliability, design for fault tolerance, prognostics, and design for maintainability. This paper reviews methods focussing on the first three, i.e. component reliability, active control, and fault tolerance. The paper further identifies some promising directions for further research.
\end{abstract}

Index Terms-Availability, reliability, wind energy, generator systems.

\section{INTRODUCTION}

$\mathrm{W}$ IND energy is playing a major role in the energy transition from fossil fuels to renewable energy. In 2015 the world saw a net increase of $17 \%$ in the installed global wind power capacity to $432 \mathrm{GW}$ [1]. Although extensive research and development has been successful in increasing the size and power production of wind turbines, there is now renewed focus on maintenance costs as they account for a quarter of the Levelised Production Costs (LPC) [2], [3].

Offshore wind turbines have additional challenges for maintenance due to the difficulty of access and the logistics involved in repair. Therefore, failures in wind turbines are not only expensive but also affect the availability of the turbine.

Increasing the availability of wind turbine generator sys-

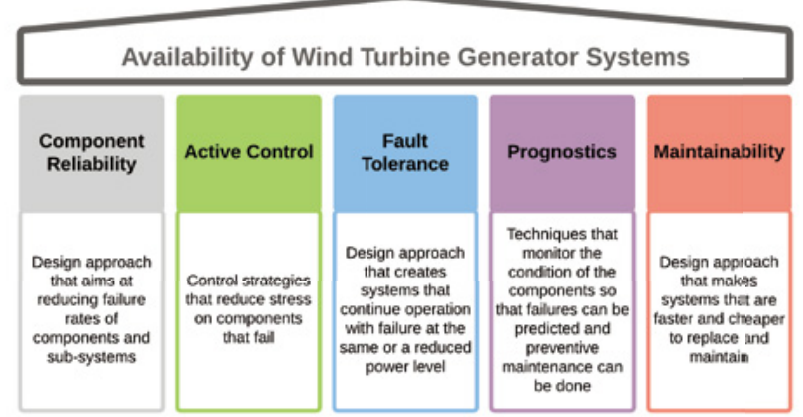

Fig. 1. How can availability in wind turbine generator systems be increased?

Manuscript received December 10,2016.

The authors are with Department of Electrical Sustainable Energy, EWI, TU Delft, Mekelweg 4, 2628CD Delft, the Netherlands (e-mail: U.Shipurkar@tudelft.nl)

Digital Object Identifier 10.24295/CPSSTPEA.2016.00007 tems is based on five pillars or approaches as shown in Fig. 1. These include the design for component reliability, active control for reliability, design for fault tolerance, prognostics, and design for maintainability. This paper focusses on the first three, i.e. component reliability, active control, and fault tolerance.

The remainder of this paper is organised in the following sections; Section II gives an overview of the failures in wind turbine generator systems followed by the mechanisms behind failures in Section III. Section IV introduces the approaches taken in this review and Section V and Section VI review the methods for improving availability for the converter and the generator. Finally, Section VII identifies some promising research directions and Section VIII draws some conclusions from the review.

\section{Failures In Wind Turbine Generator Systems}

A number of papers have studies failure rates of wind turbine assemblies [4]-[9]. These studies have shown that the generator and the power electronic converter are components of the drivetrain that have a large share of the annual failures. Fig. 2 shows this distribution.

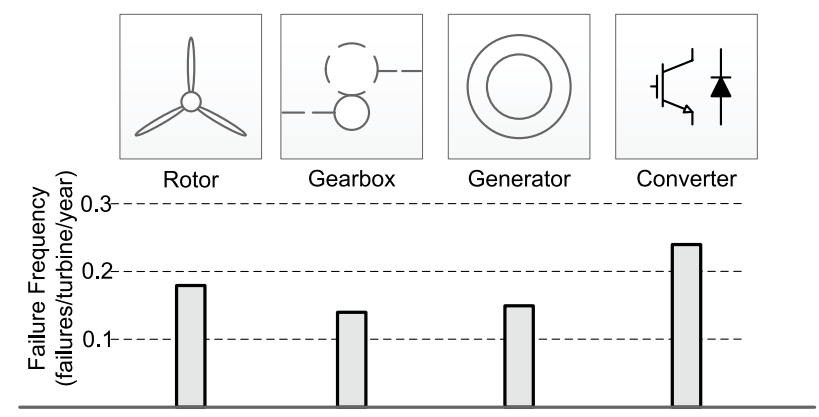

Fig. 2. Failure rate distribution in the wind turbine drivetrain. From [8].

However, to break down the failure rates to a component level failure is difficult, as there is little published data on this. Lyding et al. published a distribution of failures of wind turbine converter components in [10] which is shown in Fig. 3, while Alewine et al. published the distribution for wind turbine generators in [11] and this is shown in Fig. 4.

It can be seen that for the converter, the highest failure rates are for the power semiconductor and control. For the generator, the bearings have the highest failure rates followed by the stator windings and wedges. 


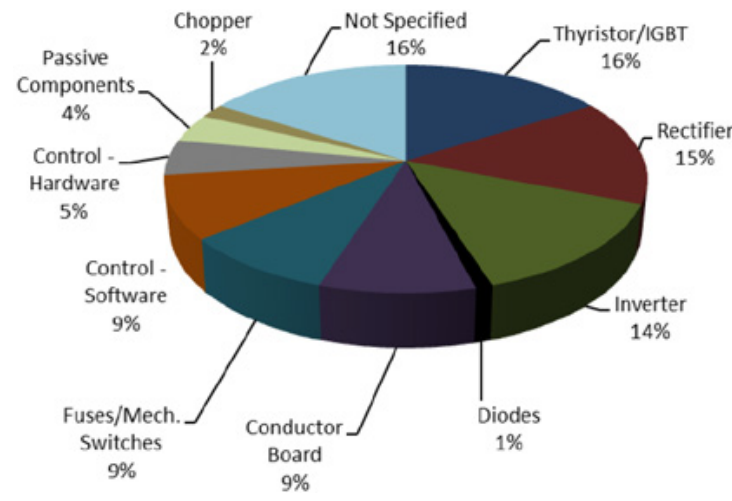

Fig. 3. Converter components failure distribution. From [10], [12].

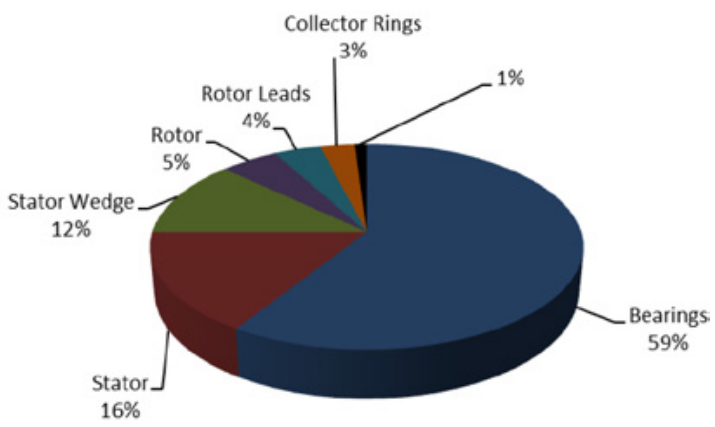

Fig. 4. Generator components failure distribution. From [11], [12].

\section{FAILURE MeChanisms}

This section describes the failure mechanisms of the converter and generator. This is based on the review in [12].

\section{A. Converter Failure Mechanisms}

The components that fail most in a converter are: the power semiconductors, the control, the passives, conductor boards, and the fuses. Here, the failure mechanisms for the semiconductors, the control, and the capacitors are discussed.

1) Power Semiconductor: Power semiconductors suffer from a number of failures such as - bond wire lift-off, bond wire heel cracking, aluminium reconstruction, corrosion of interconnections, solder fatigue and voids, latch-up and cosmic ray failures among others [12], [13].

Solder joint fatigue and bond wire lift-off are the two major failure mechanisms plaguing power semiconductors. Solder joint failure occurs due to the solder layer being subjected to mechanical stress by the materials between which the solder is sandwiched. When the power semiconductor undergoes a change in temperature, the materials on either side of the solder expand to different extents due to their different coefficients of thermal expansions (CTEs). This differential expansion gives rise to the mechanical stress in the solder layer. Similarly, the different CTEs of the bond wire and the silicon they are attached to gives rise to shear stress when subjected to temperature variations which causes the lift-off of the bond wire. A variation of the bond wire lift-off is the heel cracking where the bond wire undergoes flexure fatigue and cracks at the point of attachment to the silicon. These mechanisms are driven by temperature cycles that may be caused by thermal cycling (heating due to external sources) or power cycling (heating due to semiconductor losses).

Such temperature cycles also induce stresses on the device upper metallisation because of the CTE mismatch between it and the silicon leading to aluminium reconstruction. This becomes an issue for reliability when there are pre-existing step coverage problems at the emitter contact in the IGBT [13]. Essentially, aluminium reconstruction reduces the cross-section of metallisation resulting in an increase in the resistance of the aluminium contact.

The press-pack package technology eliminates the dominant failure mechanisms of wire bonded semiconductors like bond wire lift-off and solder joint failure. However, the differential expansion of materials under temperature cycles cause a different set of failure mechanisms such as fretting, spring fatigue and spring relaxation.

Latch-up is another failure mechanism that occurs in IGBTs. This occurs when the parasitic thyristor in the IGBT is turned on and the collector current can no longer be controlled through the gate. Static latch-up can occur due to high collector currents while dynamic latch-up occurs due to switching transients at turn off [14]. Further, failures can be initiated through self-sustaining discharges in the silicon by recoil nuclei caused by cosmic radiation. It has been shown that this is a problem for devices with a voltage class as low as $500 \mathrm{~V}$ which makes it an important consideration for wind turbine converters [15].

The failure mechanisms and their drivers are summarised in Fig. 5.

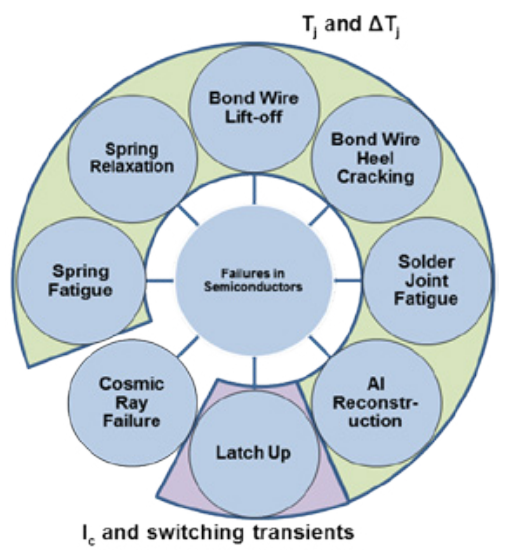

Fig. 5. Failure mechanisms in power semiconductors. From [12].

2) Control: The control unit is another component that has a high failure rate in the drivetrain. Here too the failures are driven by temperature cycles [16]. Furthermore, continued narrow overvoltage spikes between collector and emitter may open the gate-emitter resistance resulting of a loss in the driving signal and misfiring of the IGBT [16]. This can result in thermal breakdown [17]. 
Also, as modern IGBTs can work at much higher temperatures than the gate drive circuit components the driver circuit could suffer from the thermal effects in such a scenario.

3) Capacitor: Two types of capacitors are used in wind turbine converters - aluminium electrolytic capacitors and metallised polypropylene film capacitors. The electrolytic capacitor offers high power density at a lower cost but suffers from reliability issues, which requires them to be oversized, while the film capacitor offers higher reliability but has a lower power density [18].

Both Aluminium Electrolytic Capacitors and Metallised Polypropylene Film Capacitors have parameter degradation as a dominant failure mode. Capacitor voltage stress and temperature stress are two major causes of this failure mode while humidity also plays a role (especially for polypropylene film capacitors).

Capacitors can also suffer from short circuit failures that are a result of a breakdown, such as thermal breakdown. Propylene film capacitors can undergo a short circuit failure due to the absorption of moisture by the dielectric film.

Open circuit failures occur either due to electrochemical corrosion leading to lead fractures or the drying of capacitor cores when they are subjected to high working temperatures [19]. A further review of failures in capacitors is presented in [20]. A schematic overview of failure mechanisms and drivers is shown in Fig. 6.

\section{B. Failure Mechanisms in Generators}

The components that have the largest share of failures in the generator are bearings, the windings, the stator wedges, the rotor leads, and the slip ring assembly. However, this section does not discuss failure mechanisms in the generator bearings.

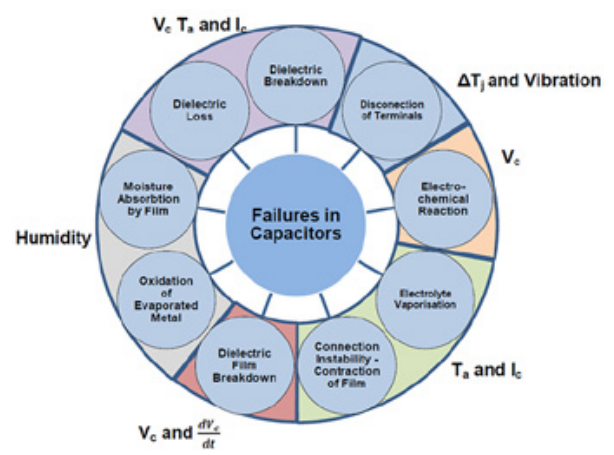

Fig. 6. Failure mechanisms in capacitors. From [12].

3.2.1. Windings: The ageing and failure of generator windings is due to thermal degradation, mechanical stress due to vibrations, electrical stress, and shear stress due to different CTEs of the winding and insulation materials [21].

Thermal ageing is a well known and modelled phenomenon. However, another factor that affects the lifetime of winding insulation is thermal cycling. This has been shown to be a factor for large generators that go through start and stop cycles, like hydro-generators [22], [23]. Kokko et al. investigated the root causes for poor and critical condition index of hydroelectric generator stator windings and found that $38 \%$ are due to ageing by thermal cycling [22]. Therefore, it can be estimated that wind turbine generators would also be affected by thermal cycling, due to the large variations in their duties. Thermal cycling causes shear stresses between the conductor and the insulation (due to their different Coefficients of Thermal Expansions) which causes mechanical fatigue. This causes the formation of voids, which result in the breakdown of the insulation. It can be expected that the stress and hence the ageing depends on the magnitude of the temperature difference in the thermal cycle. However, further study is required to confirm the effect of this thermal cycle on the insulation lifetime in wind turbine generators.

The electrical stress experienced by generator windings is intensified by the use of PWM based converters. The PWM switching regime can cause fast travelling voltage wavefronts that generate reflected waves that can cause large voltage spikes [24], [25].

The environment can also play a role in the degradation of windings. Offshore wind turbines are exposed to moisture and corrosive salt water, both of which degrade windings. Also, DFIG based wind turbines use carbon brushes whose wear can lead to carbon deposits on the windings which may also initiate surface tracking in winding insulation.

2) Stator Wedges: Alewine et al. identified the loosening of magnetic stator wedge as a major failure mechanism in wind turbine generators. The benefits of using magnetic stator wedges are - the smoothing of the air-gap flux, improved efficiency and reduced temperature rise [26]. With stator wedges being made out of magnetic material they will vibrate under the effect of rotating fields causing the weakening of the stator wedge bonding. Also, the ferrous nature of the wedges speeds up corrosion through oxidation [11].

3) Rotor leads and Slip Ring Assembly: For a DFIG based system, the power is fed to the rotor windings through rotor leads which usually run through the shaft of the generator. This can lead to thermal issues and degrade the insulation of these leads by the mechanisms discussed in the previous section. The DFIG also uses slip ring assemblies that are prone to failure. The brushes on these assemblies wear out with time, however, this wear can be unpredictable based on the operating conditions and can lead to failures. Voltage spikes can cause flash-over between rings and the insulation in these assemblies can be degraded due to thermal ageing.

\section{IMPROVING AVAILABILITY}

The availability of a wind turbine is the amount of time it is operational and produces energy in a specified period divided by the total time in that period. Availability takes into account both failure frequency and downtime into its calculation and therefore is a good measure of the power production performance of a wind turbine. 
This paper reviews the methods of increasing the availability of wind turbine generator systems. For this paper, the framework focusses on three pillars or approaches:

Component Reliability - The first approach takes into account steps that can be realised at the design stage. The design aim of increasing the reliability can be achieved by:

- Eliminating components that fail.

- Increasing the strength of components/materials so that they can sustain a larger stress.

- Reducing the stress on failure prone components.

Active Control - the second approach utilises active control strategies that reduce the stress on components. Again, the focus is on increasing lifetimes of the components.

Fault Tolerance - even with the above two approaches being employed there is the chance of failure in the system. Therefore, including fault tolerance will allow the system to continue operation under fault till maintenance and repair can be done on the machine, further increasing availability.

\section{AdDressing Converter Availability}

The framework for improving converter availability with the three approaches is shown in Fig. 7.

The focus in this section remains with the power semiconductors and improving their lifetimes.

\section{A. Component Reliability - Power Module Level}

The design for reliability can be tackled at two levels, the power module level and the converter level. At the power module level, connection techniques for interconnects and die attach are reviewed along with the baseplate design and package cooling. These aspects are shown in the schematic in Fig. 8.

1) Interconnects: Wire bonds have been shown to be a limitation for the reliability of power semiconductors. When subjected to thermal and power cycling, the flexure stress can lead to a liftoff or a crack in the heel of the aluminium bond wire; leading to failure. There are a number of methods and design choices that can improve the lifetime performance of these interconnects:

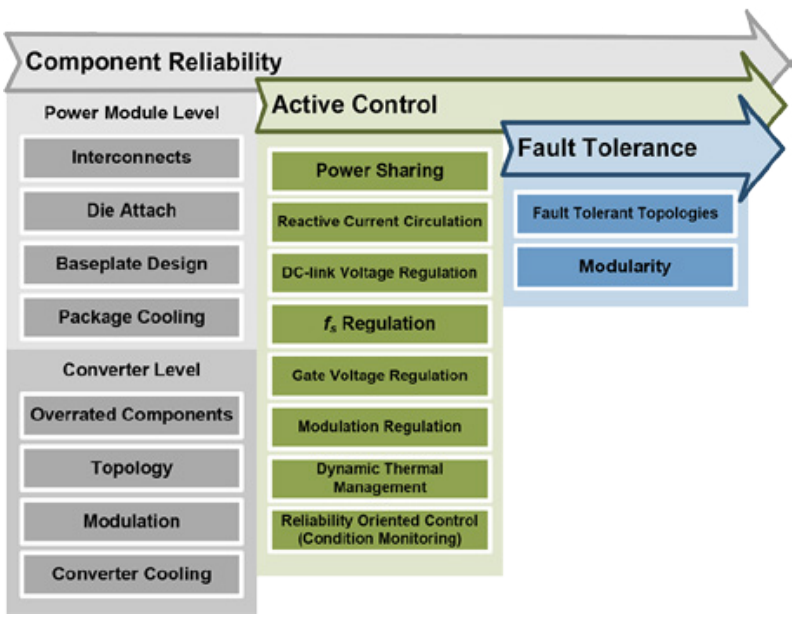

Fig. 7. Framework for increasing converter availability.
Molybdenum Strain Buffers - Bond wire failure occurs due to the stresses caused by the CTE mismatch between the aluminium of the bond wire and the silicon. This stress can be reduced by the addition of a molybdenum strain buffer soldered to the chip [27], [28]. The CTE of molybdenum is close to that of the silicon chip, which reduces the thermal stress and improves the lifetime. Hamidi et al. showed that the introduction of these strain buffers could increase lifetimes by a factor of 2-3 [27].

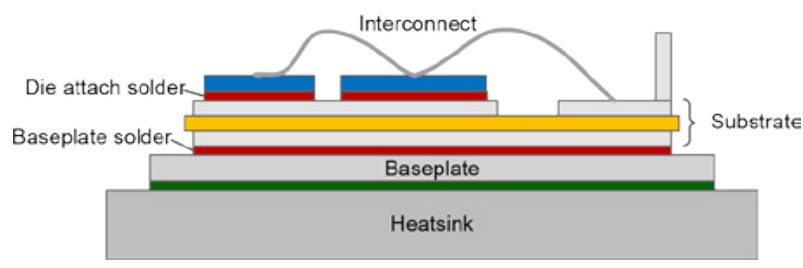

Fig. 8. Schematic of the power semiconductor module.

Copper Wire Bonding - In the heel cracking failure mechanism the crack develops in the aluminium bond wire near the semiconductor surface and propagates along the grain boundaries. An increase in the yield strength of the bond wire material will allow the interconnection to sustain the thermal stresses for a longer period of time. Copper is therefore a suitable choice and can increase the lifetimes of bond wires by an order of magnitude under certain test conditions [29], [30]. Fig. 9 shows an example of copper wire interconnects. The use of copper wires will require a change in the aluminium topside contacts on the chip. Therefore, the use of copper wires cladded with aluminium (an example for this is shown in Figure 10 for ribbon bond wires) allows the use of standard chip contacts while increasing the lifetime of the bond wires [31], [32]. Also, research on other materials, usually alloys of aluminium, as a replacement to aluminium have shown promising results [33], [34].

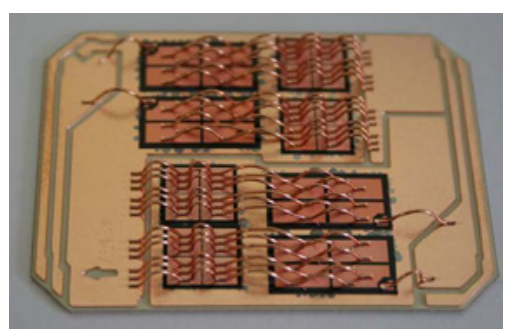

Fig. 9. Copper wire bonds on $\mathrm{Cu}$ metallised IGBTs. Figure from [30].

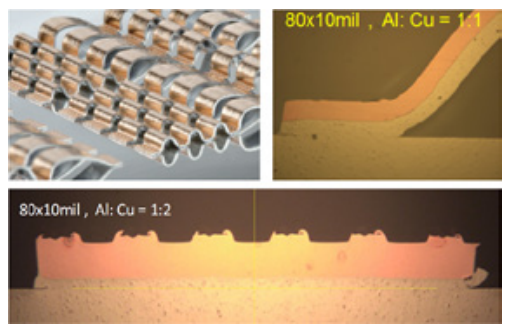

Fig. 10. Al-Cu ribbon bonds. The figure shows crosssections of ribbon 
bonds with different $\mathrm{Al}: \mathrm{Cu}$ thickness ratios. Figure from [32].

Ribbon Bonding - This technique makes use of rectangular ribbons of bond wire (Fig. 10) in place of the round bond wires. This allows better contact with the surface of the die area and lower thicknesses which improves the ultrasonic bonding process [35]. The study in [36] found that lifetime with a ribbon bond wire is 2.3 times that of a round wire bonded technology. This is attributed to the higher contact surface and stiffness which reduces crack propagation.

Sintered Interconnects - This technique eliminates the need for wire bonds by sintering the top side of the power chip to a connector. The connector may be in the form of flexible circuit board (Fig. 9) as in [37], [38] or planar copper interconnects (Fig. 12) as in [39], [40]. Such an interconnection gives the opportunity for double-sided cooling that can greatly increase the cooling efficiency.

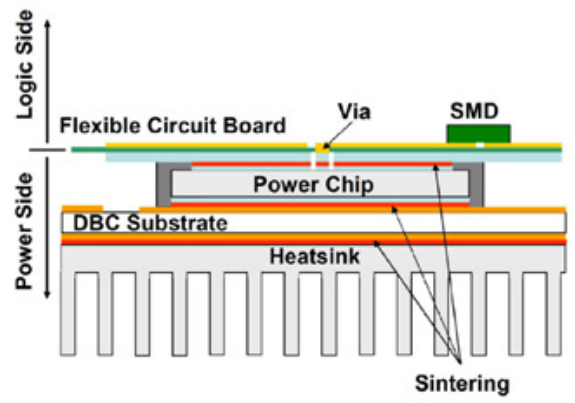

Fig. 11. Planar interconnects with flexible PCB. Figure from [38].

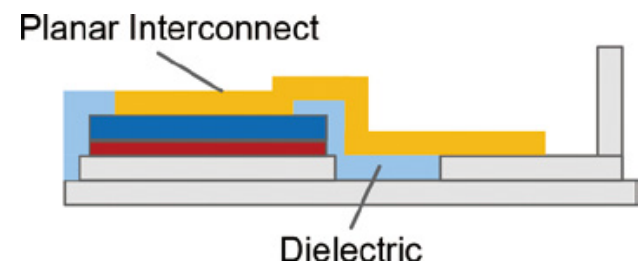

Fig. 12. Planar copper interconnects. Based on [40].

Press-pack - The press-pack technology uses pressure to obtain electrical and thermal contacts, thus eliminating wirebonds and minimising solder connections. Studies in [41] showed that press-pack IGBTs have improved lifetime performance compared to the flat-pack IGBTs. However, [42] found early failures that could be attributed to damaged gateoxide and micro-eroding. The press-pack also addresses the solder fatigue failure mechanism.

2) Die Attach: In a power semiconductor, the silicon die is in most cases attached to the substrate by a solder layer. This introduces a failure mechanism driven by temperature cycles leading to solder fatigue. In [43] it is shown that for power cycling tests with $\Delta T_{j}<100 \mathrm{~K}$ the solder fatigue failure mode dominates. Therefore, for wind power applications this failure mode should be the focus for the design for reliability approach.

There are a number of replacements for the conventional lead based solder that have the potential of improving the lifetime with respect to solder fatigue. The use of new solder material such as the lead-free tin-silver based solder in [44] can be one solution, although it brings its own challenges. Another possibility is the use of diffusion bonding which forms bonds based on intermetallics leading to improved performance against thermo-mechanical loading [30], [45]. Fig. 10 shows the cross section of such a diffusion soldering sample.

Another promising technique for the die attach is silver sintering where micro or nano silver particles are applied between the die and the substrate followed by the sintering process resulting in a metallic bond [45]. A number of studies have shown the improvement in lifetime performance of silver sintered joints compared to solder joints [45]-[48].

Further, a more focussed and detailed review on the die attach methods and materials can be found in [49].

3) Baseplate Design: The power semiconductors have a solder layer between the ceramic substrate and the baseplate. This layer undergoes fatigue under cycling of temperature due to the different expansions the ceramics and the baseplate undergo. This fatigue can be reduced by matching the CTEs of the ceramic substrate and the baseplate. This can be achieved by the use of AlSiC baseplates with AlN substrates. This can reduce reduce fatigue on the solder and increase lifetime [50]-[52]. However, this comes at the cost of higher temperatures due to the lower thermal conductivity of AlSiC compared to copper [52].

4) Package Cooling: As failures in the power semiconductor are temperature driven, effective cooling can enhance reliability. One way to do this is the use of microchannel based water cooled baseplates. [53] shows a $60 \%$ reduction in thermal resistance compared to a standard module. This can be extended to jet impingement cooling for the baseplate or the substrate itself [54] with both methods thermally outperforming modules with cold plate technology. The integration of metallic phase change material into the design of the chip silicon as in [55] or the integration at the DBC level as in [56] could also be explored. Furthermore, the use of modules designed as a sandwich between two DBC layers for double-sided cooling as in [57], [58] could

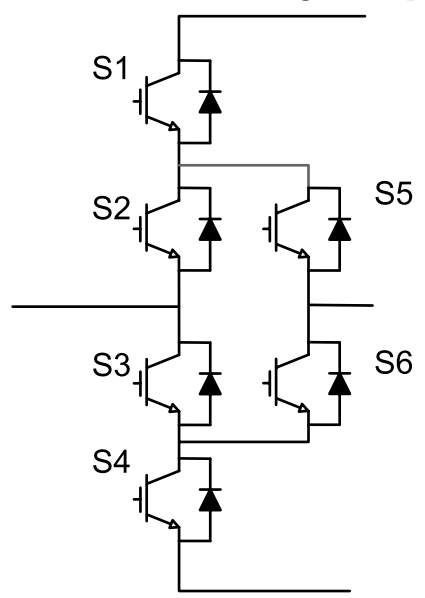

Fig. 13. 3L Active Neutral Point Clamped (3L-ANPC) topology leg. The additional switches S5 and S6 allow the even distribution of losses. 
result in large improvements in thermal performance.

\section{B. Component Reliability - Converter Level}

At the converter level, the use of overrating, topology, modulation and converter cooling are discussed.

1) Over-rating: For power semiconductors, the failure mechanisms are driven by the cycling of the junction temperature and the mean junction temperature. The use of multiple parallel converters, which would overrate the switches in use, or the use of switches with a higher rating would reduce the junction temperatures and hence boost reliability. This has been explored for PV systems in [59]-[61] and can be extended to wind turbine systems.

2) Topology: The choice of topology can also have an effect on the lifetime of the power semiconductor. The three-level Neutral Point Clamped (3L-NPC) converter is a popular choice for large power wind turbines. This topology has an uneven distribution of losses amongst the semiconductors in each leg. Therefore, topologies that can evenly distribute the losses, and hence the stresses on the semiconductors would result in an increased lifetime of the converter. For this, the T-type and the Active Neutral Point Clamped (ANPC) topologies are promising [62].

Furthermore, the number of converter levels can be extended further than 3 . This would introduce additional switching states in the operation and improve thermal performance thereby improving reliability as has been shown with a five-level converter in [63].

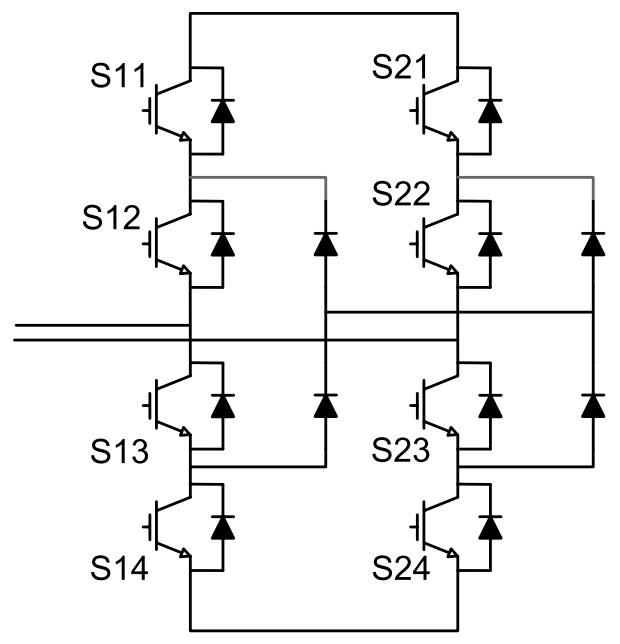

Fig. 14. 5L H-Bridge topology leg. The additional levels reduce the losses in the switches.

3) Modulation: The use of the Discontinuous PWM modulation technique can reduce the effective switching frequency of a converter and increase lifetime. This use of this modulation strategy has been shown to have a modest effect on the lifetime of the converter for DFIGs in [64]. However, the DPWM leads to increased current harmonics at low modulation levels.

The use of optimal modulation schemes can reduce switching frequencies without increasing harmonic dis- tortion. Reducing switching frequency results in lower losses in the semiconductor which is advantageous from the point of view of reliability. The Synchronous optimal PWM (SoPWM) is one such technique that has been explored and has been shown to be successful in reducing the switching frequency without affecting the harmonic distortion [65][67].

4) Converter Cooling: The thermal management of the converter is important not only from the point of view of the power semiconductors, but also the other sub-components like the capacitors as well. A number of failure mechanisms in these sub-components can be linked to temperature and therefore, methods that can improve thermal management of the converter can be beneficial for the overall reliability of the converter. The power sandwich integration is one such concept [68], [69] that uses new passive components that have equal heights and are sandwiched between two substrates allowing heat transfer in both directions.

\section{Active Control}

Once the converter has been designed there are still opportunities where active control methods can be applied to reduce the stress on components.

1) Power Sharing: Today's large wind turbine converters are built up of multiple modular converters in parallel to handle the large amount of power they need to process. The variation of components in these converters, even within the tolerance limits, may lead to a variation in junction temperature amongst the parallel converters. This would lead to larger stresses on certain converters and drive them to premature failure. However, if the power processed by each converter is partitioned on the basis of the temperature of the components as in [70], [71], the stresses on converters can be reduced and lifetimes extended. Therefore, the control strategy is based on equalising temperatures in converters rather than current. This method is also shown to improve efficiencies compared to current sharing controls in [72].

2) Reactive Current Management: Today's wind turbines are required to support the grid with reactive power injection. This can have a significant effect on the lifetimes of the converters. For a DFIG based system, this reactive power injection can be achieved from the grid side converter or the rotor side converter via the stator circuit. [73] shows that injection of reactive power from the rotor side converter produces less current stress and is, therefore, better for lifetimes. Furthermore, [74] optimises the reactive power flow between the grid and rotor side converters to achieve an overall balanced lifetime.

The reactive current can further be used to minimise temperature variations in the power semiconductors of the converter. [75] explores the circulation of reactive power between the rotor side and the grid side converter of a DFIG based system resulting in lower temperature variations during normal operation as well as during gusts. [76] explores this circulation of reactive power between parallel connected converters for full converter based wind turbines 
to significantly reduce temperature variations during wind gusts.

3) DC-link Voltage Regulation: A DC-link regulation strategy adapts the DC-link voltage to the requirement of the operating point. Such a strategy can reduce losses in the converter significantly resulting in reduced junction temperatures and therefore; increased lifetime. The DClink voltage regulation strategy can be used in conjunction with the other methods described in this section to further increase the effect on lifetime. This has been implemented for traction drives in [77].

4) Switching Frequency Regulation: The losses in a power semiconductor are dependant on the switching frequency. Therefore, the control of switching frequency can be used to regulate the temperature of the device.

First, the switching frequency can be used to ensure that semiconductor temperatures remain within the safe limits. As the junction temperature rises to a set value, the switching frequency can be reduced. This would reduce losses and hence protect the semiconductor from overheating. Such a system has been proposed in [78] and for traction applications in [79].

Another regulation method uses the frequency to reduce the amplitudes of temperature cycles in converters. A hysteresis controller is used to regulate switching frequency according to the amplitude of the temperature cycling with the frequency being increased as temperature cycle amplitude reduces, leading to a smaller temperature cycle. A number of variations of this control strategy are available in [80]-[83].

5) Gate Voltage Regulation: Like with the power sharing method, the gate voltage regulation can be used to prevent thermal imbalance in parallel connected converters. This is achieved by adjusting the gate voltage or the gate resistance. [84], [85] show such systems for the thermal balance of parallel connected converters by active gate control.

Active gate control can also be used to control the amplitude of temperature cycles in the power semiconductor. [86] uses a system of switchable gate resistors such that the largest gate resistors are selected when the current is at the low magnitude points while the lowest gate resistors are used at high currents. This results in slow switching at low current magnitudes and fast switching at high currents resulting in reduced losses. The reduction in temperature cycle amplitude was experimentally validated. Apart from controlling the gate resistance, the control of gate voltage can also be used to regulate losses as proposed in [87].

6) Modulation Regulation: The Discontinuous PWM (DPWM) has been discussed in section 5.2.3 and has been used to reduce losses in a converter. Using a combination of the Space Vector PWM (SVPWM) and DPWM, the switching losses can be varied within a certain band. This can be used to reduce the junction temperature cycling amplitude. This Hybrid Discontinuous PWM (HDPWM) technique has been discussed and shown to be effective in [88]-[90].
7) Dynamic Thermal Management: The active control methods discussed above are based on controlling electrical parameters. Another opportunity for active control lies in the thermal management system.

[91] proposes such a system that provides adaptive cooling where the efficiency of the cooling system can be adjusted based on the temperature of the power semiconductor. Such a dynamically controlled thermal system can reduce junction temperature cycles leading to higher lifetimes. Furthermore, active cooling regulation by control of forced air speed has been studied in [92], [93].

8) Reliability Oriented Control: Conventional control schemes for wind turbines are based on the extraction of maximum energy from the wind. However, considering the cost of maintenance for far offshore wind turbines, it may be important to look at reliability oriented control strategies or condition based operation that looks to maximise the availability of the wind turbines rather than maximise the power production at each instant. Such a system is conceptualised in [94], [95].

One possibility is to use a de-rated power curve to reduce the stresses on the converter or generator. For offshore wind turbines, once a failure occurs, there can be considerable time lost in the logistics of organising maintenance visits. If a de-rated power curve would result in lower stresses allowing the converter to operate for a longer period, it could result in an overall improvement in power production. This approach could be extended such that the de-rated power curve is designed to allow the operation of the converter for a longer period, wherein the component is replaced only in the next maintenance visit. These two approaches are represented in Fig. 15.

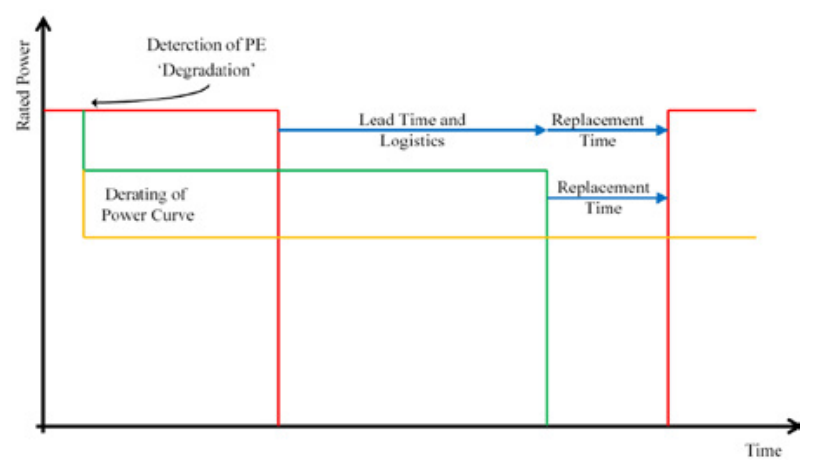

Figure 15: Opportunities for increased availability using the de-rating of power curves.

This active control technique would require inputs from the prognostics or condition monitoring mechanism.

\section{Fault Tolerance}

This section discusses two aspects of achieving fault tolerance in the converter - fault tolerant topologies, and modularity. This section is based on the review of modularity in [96] and fault tolerance in [97].

1) Fault Tolerant Topologies: There are a number of 
topologies that can be used to make the converter system tolerant to faults. A review of such topologies can be found in [98]-[100]. Fault tolerant topologies use redundancy in one form or another to introduce fault tolerant capabilities.

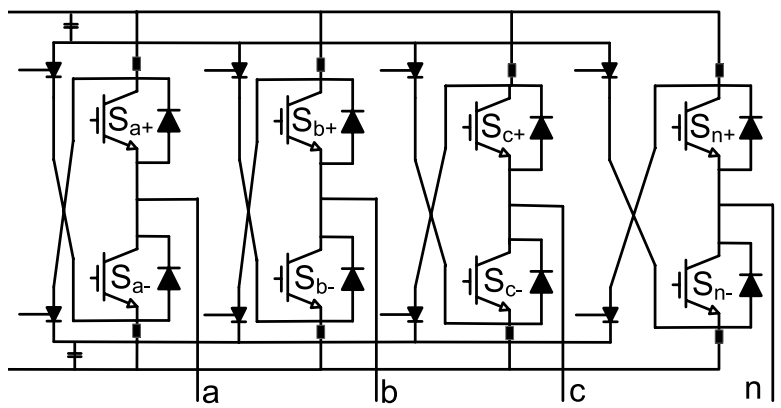

Fig. 16. Double switch redundant topology.

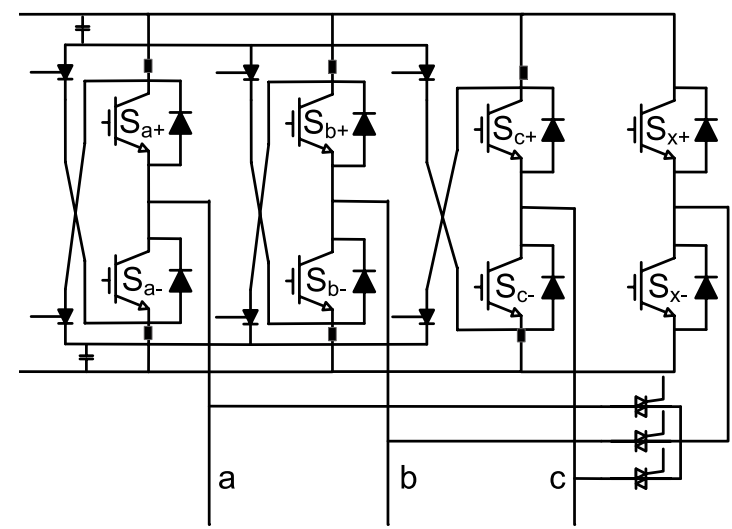

Fig. 17. Phase redundant topology.

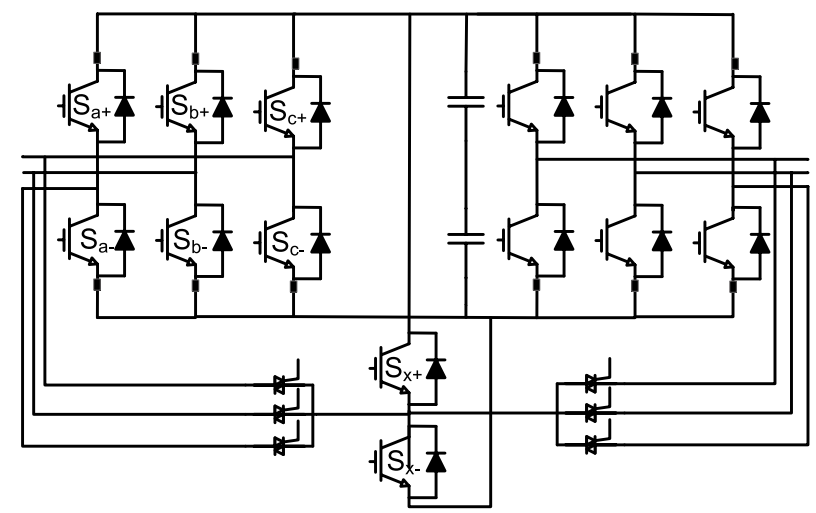

Fig. 18. Phase redundant topology with a common redundant phase leg.

The switch redundant topology introduces extra switches to the two-level converter to make it able to accommodate open phase and switch short circuit faults. The double switch redundant topology (Fig. 16) adds an extra leg connected to the neutral point of the machine. This has the advantage of making the converter tolerant to switch short and open circuits along with phase leg short and open circuits. However, the power handling capability of the topology is reduced. The phase redundant topology (Fig. 17) adds and extra phase leg that can be connected to any leg of the machine by triggering connecting switches. This topology too is tolerant to most types of faults and is capable of handling rated power.

In back to back converters, the phase redundant topology can be used with a common redundant phase leg for both (Fig. 18), the generator side and the grid side converters [101]. This reduces the overall cost for redundancy without affecting the fault tolerant capability. Furthermore, a converter topology without redundancy but with the possibility of reconfiguration which allows operation after a switch fault as a five-leg converter is proposed in [102].

2) Modularity: This section is based on the review of modularity in [96]. The use of multiple modules in a converter also introduces a degree of redundancy in the system. In the event of a failure in a module, it can be disconnected from the system and allow the rest of the converter modules to process the generated power. As wind turbines operate at partial load for significant periods of time, such a system can be especially attractive. Modularity can be introduced in two layers - the first is the functional layer, where the modules operate as separate functional blocks. The second is the physical layer, which builds on functional modularity by adding physical separation.

[16], [103] discuss the use of six parallel converter modules for a $4.5 \mathrm{MW}$ turbine. The study shows that the system not only increases efficiency and reduces grid harmonics, but it also boosts availability when mean time to repair is considered. [104] shows the improvement in reliability with modular converters using Markov models.

One method of increasing the modularity of the system is the use of tooth wound concentrated modular windings with a converter unit. This system brings in modularity both in the converter unit and the generator unit. There have been a number of applications where such a system has been employed as a means of incorporating fault tolerance. [105][107] uses this design concept for traction applications and [108] uses this for aerospace applications.

With a high level of physical modularity, such as with modular stator windings with independent $\mathrm{H}$-bridge converters for each coil, there is an opportunity to design compact converters that would reduce replacement costs. Converter modules can be designed so that they can be replaced by a single worker without heavy lifting equipment. This would increase the maintainability of the converters and increase the availability of the converter system [96].

\section{AdDRessing Generator AvaILABILITy}

The framework for improving generator availability is shown in Fig. 19.

\section{A. Component Reliability}

Considering the major sources of failure in the generator, this section discusses design solutions for the magnetic stator wedges, slip ring assemblies, winding insulation, bearings, and cooling systems. 


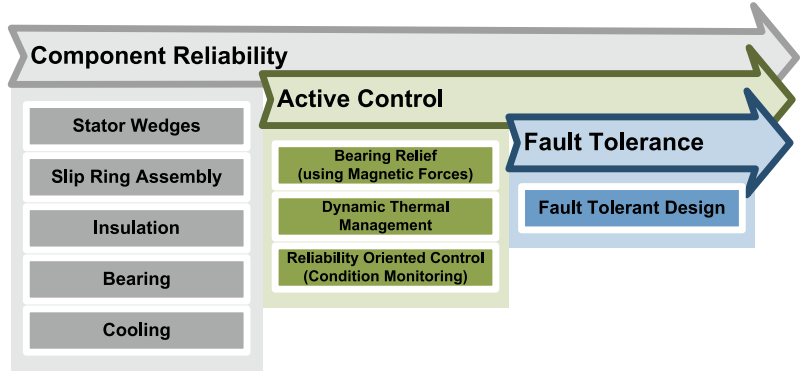

Fig. 19. Framework for increasing generator availability.

1) Magnetic Stator Wedges: A study of failures of wind turbine generators and found that approximately $15 \%$ of failures in generators rated above $2 \mathrm{MW}$ were due to stator wedges [11]. One explanation of this is that when magnetic stator wedges are used, they are subjected to pulsating forces which speed up the failure process.

Magnetic wedges offer a number of improvements to machines resulting in increased efficiency [109], [26], [110]. However, looking at their propensity to failure in wind turbines, it may be important to look at their impact once again. In this paper, analytical models were used to compare the performance of wind turbines with and without magnetic wedges based on generator designs in [111]. The comparison includes the DFIG with a three stage gearbox, and the permanent magnet direct drive. The results of this comparison are shown in TABLE I.

These results show that the advantage offered by the inclusion of magnetic wedges is small. Therefore, replacing the magnetic wedges with non-magnetic wedges could increase reliability without a large effect on energy production, leading to a net reduction in Cost of Energy (CoE).

TABLE I:

Effect of Magnetic Stator Wedges on Electrical Performance.

\begin{tabular}{|c|c|c|}
\hline & $\begin{array}{c}\text { DFIG } \\
\text { 3-stage Gearbox }\end{array}$ & $\begin{array}{c}\text { PM } \\
\text { Direct Drive }\end{array}$ \\
\hline \multicolumn{3}{|c|}{ Without Magnetic Stator Wedges } \\
\hline Annual Energy Yield (GWh) & 7.73 & 8.04 \\
\hline \multicolumn{3}{|c|}{ With Magnetic Stator Wedges } \\
\hline Optimal wedge & 9.1 & 10 \\
\hline Annual Energy Yield (GWh) & 7.73 & 8.05 \\
\hline Difference in Annual Energy Yield (MWh) & 0.97 & 8.42 \\
\hline Equivalent hours of Energy Production & 1.1 & 9.16 \\
\hline
\end{tabular}

2) Slip Ring Assembly: The brush and slip ring assembly is a major contributor to failures in DFIG based wind turbine systems. According to [112], more than half the failures in DFIGs are brush-slip ring failures. Even though more than half these failures are classified as minor repair based, for far offshore wind turbines minor failures can be very expensive as well. This failure mode can be addressed by either doing away with the slip ring system or by improving the design such that it fails less often. Apart from the slip ring in the generator, turbines that use electrical pitch actuators require power transfer to the rotating hubs thereby requiring slip ring assemblies as well.

Brushless DFIG - The B-DFIG is yet to be commercialised for use in wind turbine generators. A $250 \mathrm{~kW}$ has been designed and tested in [113]. The B-DFIG eliminates the need of brushes and slip rings. This can be especially beneficial for wind turbines in offshore applications. Due to the structure of the B-DFIG design, it has higher values of leakage inductance, which results in lower efficiencies [114]. However, the trade-off between higher reliability and lower efficiencies needs to be explored further. Another advantage of the B-DFIG is its improved low voltage ride through capability [115]. The B-DFIG is able to handle low voltage events without the use of an extra crowbar circuit. Therefore, the power electronic converter is protected without the use of extra components, improving reliability.

Brushless Excitation - The slip ring assembly can also avoided by the use of brushless excited machines. Apart from the permanent magnet synchronous machine, the use of rotary transformers for contactless power transfer to the rotor is also a solution. Examples of the design of such systems can be found in [116], [117].

Lubricated Slip Ring Assemblies - In sliding contacts, the conduction takes place across an insulating film (which is a moisture film in many applications) by the tunnel effect. In the absence of such a film, the two clean metallic surfaces will cold weld such that the surfaces will be destroyed during sliding and the wear on the brushes will be very high [118]. One of the ways of improving the wear resistance of the brush-slip ring assembly is by the use of boundary lubrication. This is done through the formation of thin films on the contact surfaces that do not strongly affect the current but reduce the wear [119]. The use of oil that is a suspension of conducting particles has been shown to have good results [120]. Apart from improving the wear characteristics, a good lubricant could damp vibrations leading to lower noise levels in the transmitted signal (this is more important in the use of slip rings for signals and instrumentation) as well as act as protection against corrosion of the slip ring assembly. As wind turbines, especially those erected offshore, operate in harsh and corrosive conditions (salt spray etc.) protection from corrosion is an important aspect of lubricants in slip ring assemblies for wind turbines.

3) Insulation: Thermal degradation is a dominant factor in the ageing of electrical machine winding insulation systems [121], [122]. Lifetimes of insulation can be estimated using the Arrhenius rate law. The thermal class of the insulation has an effect on the lifetime. Therefore, using an insulation with a higher thermal class would increase the life expectancy of the insulation.

The use of PWM based converters can cause electrical stresses in the insulation due to the voltage spikes created 
by the fast front voltage waves [24]. Further, this large dV/ $\mathrm{dt}$ due to switching of the converter can give rise to large capacitive currents in the insulation, and voltage gradients in within windings. [123] gives an overview of possible solutions for relieving these stresses. These solutions could be design choices like the length of connecting cables, the switching speed, the machine insulation material as well as the use of additional components like filters.

4) Bearings: Bearings are a major reason for failures in wind turbines. The causes of failure may be due to problems in lubrication, contamination, misalignment etc. The solutions to such problems are beyond the scope of this paper.

However, another reason for accelerated bearing wear is bearing current. These bearing currents can be produced by high motor frame voltage due to common mode current, high frequency axial shaft voltage due to circumferential magnetic flux around the motor shaft, the coupling of common mode voltage via the bearing capacitances [124]. It is possible to prevent the discharge of current through the bearings by using insulation in the bearings or by creating alternative paths for the current like using a grounding brush [124], [125]. Furthermore, converter design to minimise the common mode voltage can also help reduce bearing currents [126].

Eccentricity in the machine rotor may be caused by a manufacturing defect or from wear in the bearings. This eccentricity causes Unbalanced Magnetic Pull (UMP) which can further effect an increase in bearing wear. This UMP is damped to some extent by the cage in the caged induction machines and by the pole dampers in synchronous machines [127], [128], however, wound rotor machines (like the DFIG) can still benefit from the addition of damper windings. The use of stator damper windings to attenuate UMP in induction machines has been investigated in [129].

5) Generator Cooling: As the temperature is the main driving factor for insulation ageing, improved cooling systems for generators would prolong lifetimes of windings. Liquid cooling is one such technology that can give good results. Many high power wind turbines today already use liquid cooling for the generator and converter [130]. This cooling performance may be improved by using hydrogen cooling as in [131].

Another possibility is to use liquid flow within the stator winding to remove heat. This uses hollow conductors which allows the cooling liquid to flow within them and remove heat straight from the source. Such a system has been proposed in [132] and [133].

\section{B. Active Control}

This section looks at opportunities for reducing stress on components of the wind turbine generator.

1) Bearing Relief: The issues with bearings have already been discussed in Section II. It is evident that improving the life of bearings can have a major impact in improving the availability of wind turbines as they account for the highest downtime for any wind turbine component [8].

One of the ways of addressing the bearing failures is the use of the inherent magnetic forces in the machines to reduce the load on the bearings and hence accomplish bearing relief. For large direct drive generators, the weight of the rotor is carried by the generator bearings. The use of magnetic forces to take this load off the mechanical bearing would reduce their wear and hence increase their lifetime. Here, the weight of the turbine and the moments generated by it would have to be handled. The reduction of bearing forces can be achieved by using a number of methods of which the use of passive damper windings has been discussed in section the Part 4 of Subsection A in Section VI,

Control Windings - One possibility is the use of an additional winding in the stator which can be controlled to produced the required radial forces. This may be compared to a magnetic bearing or bearingless machine, however, the idea here is to keep the mechanical bearing and only use the additional winding to reduce the load on the bearing thus reducing the load handled by such windings. One of the disadvantages of such a system is the additional need for control. This would require the addition of power electronic converters, controllers and sensors [134]. A system that uses additional windings to generate radial forces and cancel the rotor weight to effect bearing relief has been investigated in [135].

Active Generator Control - Another option is the use of control schemes in existing machine systems to reduce the rotor radial forces [136]. This would have the advantage of not requiring additional windings, however, it would make the control of the machine more complex. The use of modular machine concepts (with tooth wound generators with independent h-bridge converters for each turn) could be extended to include active generator control to counteract the weight of the rotor and reduce the load on the bearings. The use of sensorless control would also reduce the need of sensors and have been proposed in [137], [138] for small bearingless machines.

Furthermore, the use of active magnetic force control in modular generators also afford the opportunity to counteract dynamic bearing forces that may arise, for example, due to wind gusts. The challenge here is being able to measure the stress in the bearing system to be able to counter them.

2) Dynamic Thermal Management: It has been discussed in Part 1 of Subsection B in Section III that temperature cycling of the winding could lead to accelerated failure, therefore, dynamic thermal management as discussed for the converter in Part 7 of Subsection C in Section V could reduce the temperature cycling.

3) Reliability Oriented Control: Reliability based control or condition based operation has been described in Part 8 of Subsection C in Section V and can be used to extend the lifetime of generator components as well. [139] explores a prognostics based life extension methodology for generation systems and focusses on the bearing system. 


\section{Fault Tolerance}

This section is also based on the review of modularity in [96] and fault tolerance in [97]. For a machine to be tolerant to its failures, it has to satisfy certain requirements [140],

Electrical Isolation - To limit the effect of the faulty winding on the healthy part of the machine, the different 'modules' of the machine should be electrically isolated. For modular systems that use independent converters for each module (be it a single coil or three phase coil module) this requirement is already built into the design.

Limiting Fault Current - If the short circuit fault occurs at the machine winding terminal or in the converter, both scenarios could result in a very large currents. To limit the fault current, stator phase inductance has to be designed to be close $1 \mathrm{pu}$ inductance so that fault current is limited to the rated value. Furthermore, techniques for reducing the short circuit current by using magnet subdivisions have been investigated in [141], [142].

Magnetic Isolation - Fault current will induce a voltage in the neighbouring phases, because of the presence of mutual inductance between phases. This would make control of the machine difficult. To reduce the effect of one phase on another, the mutual inductance between phases or modules must be small.

Thermal Isolation - Short circuit current can produce large amounts of heat in the slot, therefore, thermal isolation between the different windings is recommended. Modular stator windings with a single coil in each slot would serve this need well.

The use of a modular design with a distributed control architecture with multiple processors would allow operation under the failure of control modules as well. The addition of physical modularity to the generator design by using segmented cores introduces the ability of a core module of the generator being replaced in case of any winding failure. Stator winding failures account for about $20-30 \%$ of all generator failures [11]. These failures are expensive to fix and take considerable time. According to [8], a generator failure averages about 150 hours of downtime. The use of segmentation would reduce the time and cost of faulty winding replacement. Physical modularity in the form of segmentation could, therefore, be especially attractive for offshore wind turbines [96]. Such a system is proposed in [143] where the direct drive PM generator is constructed from physically separate E-core modules as shown in Fig. 20 .

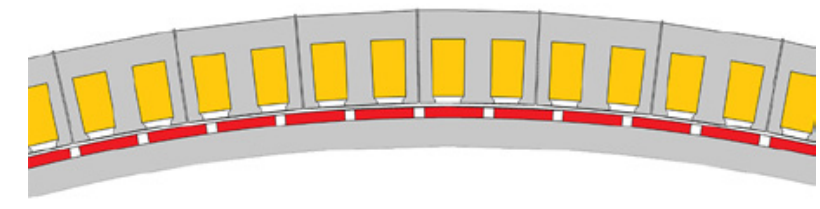

Fig. 20: Physical modularity in the generator.

Fault tolerance can also be included by the use of multi- ple phases. [144] describes an AC drive with multiple independent phase driving units. For wind turbines, such a multiple phase system with nine phases constructed with classical three phase converters was described in [145].

\section{Promising Research Directions}

The previous sections have reviewed some methods that aim to increase the availability of wind turbine generator systems by the design for component reliability, the active control for reliability, and the design for fault tolerance approaches. This section highlights those methods that the authors are working on and consider promising directions for investigation.

Converter Design for Reliability - The use of design concepts at a converter level to increase reliability can be applied to commercially available power modules. Even with advancement in power module technology, the failure mechanisms are still driven by thermal and power cycling (the examples being press-pack technology, silver sintering methods etc.). Therefore, with the advances in power module technology, these design concepts will only help boost the reliability of the converter (until other failure mechanisms become the limiting factor in reliability).

A number of avenues for further research exist in this field. First, a comparison of the effects of overrated components and overrated topologies on the lifetime of the converter is required. This will allow the identification of an optimal topology from the point of view of reliability. Further, the use of dynamic switching strategies that distribute the losses based on the temperatures of the semiconductors can be investigated.

Dynamic Thermal Management - Many active control methods use the control of electrical parameters to reduce the amplitude of temperature cycles in the junction of the power semiconductors $\left(\Delta T_{j}\right)$ and increase the lifetime. The essence of this concept is to increase the losses when the junction temperature is low so that $\Delta T_{j}$ is reduced. However, the reduction of $\Delta T_{j}$ can also be achieved by controlling the effectiveness of the thermal circuit. Without the need to increase losses, this method has the potential of improving the lifetime without considerable effect on the efficiency of the converter. The case for the use of dynamic thermal management is further strengthened by the fact that a majority of wind turbine converters already use liquid cooling. Therefore, aspects of this method can be included into the design without major re-engineering.

There are a number of opportunities for research in this field. First, different configurations that are possible need to be identified and evaluated. One possibility is the use of the generator as thermal capacitance by the integration of the converter and generator cooling circuits. This could be used to counter medium term temperature cycles. Another possibility is the use of differential heat production in separate parts of the component for dynamic thermal management i.e. use heat from one place to reduce thermal efficiency at another. 
Fault Tolerance with Modularity - Systems, no matter how well designed, can suffer from random failures. This is more so in the case of complex systems like wind turbines. Therefore, the use of fault tolerant design can play an important role in increasing the availability of such systems. Modularity is interesting because it is already used to some extent in large wind turbine generator systems. Furthermore, the use of modularity can benefit other aspects such as maintainability and the installation of generator systems.

This area of research presents a number of opportunities some of which have been listed in [96]. These include: the design of compact physically modular converters that can be replaced by a single worker without heavy lifting equipment, a detailed investigation of physically modular generator topologies for use in wind turbines, and the optimal sizing of generator modules considering electrical, structural, and post fault performance. Further, as the converter has a majority of the failures when compared to the machine winding, it must be investigated if the generator needs to be designed for fault tolerance.

\section{CONCLUSIONS}

The increased availability of wind turbine generator systems is based on five pillars - design for component reliability, active control for reliability, design for fault tolerance, prognostics, and design for maintainability. This paper has reviewed methods focussing on the first three pillars and identified a few promising directions for further research. With a holistic approach based on these five design approaches, methods can be adopted at each level such that they result in the required availability with an acceptable increment in the cost.

Further, the following conclusions are made for the wind turbine power electronic converter:

A majority of the failure mechanisms are driven by junction temperature and the amplitude of junction temperature variation. Therefore, the methods described under the design for components reliability and the active control for reliability approaches focus on these issues.

Methods for design for converter reliability are promising because they address reliability at a system level and can be applied with advancing technology as long as temperature is the driving factor in failures.

Dynamic thermal management reduces the amplitude of junction temperature cycles without significantly increasing the electrical losses. Furthermore, a comparison of electrical parameter control and thermal control based on the improvement in the lifetime as well as the electrical performance is required.

Reliability oriented control (or condition based operation) can be used to reduce the maintenance costs by allowing operation of the converter until the next scheduled maintenance visit. Thus, removing the need for unscheduled maintenance visits.

Fault tolerance through modularity is also promising because apart from the advantage of fault tolerance, it can improve the maintainability of the converter.

Also, the following conclusions are made for the wind turbine generator:

Choices in the design of the generator can have a large impact on the reliability of the generator. The examples of this are the use of non-magnetic stator wedges, and the use of brushless excitation.

Bearing relief from the dynamic forces could be an important step in improving the lifetime of generator bearings. However, the real-time identification of the stresses is a challenge that has to be overcome for this.

Dynamic thermal management can be used to reduce temperature cycling stresses on the winding insulation. However, further studies are required to confirm the effect of the temperature cycling stresses on the insulation lifetime in wind turbine applications.

Modularity in the generator system can be used to improve maintainability as well as the ease of installation. However, the trade-off between the maintainability, the electrical performance, and the structural requirements needs analysis.

\section{REFERENCES}

[1] GWEC, "Global Wind Statistics 2015,” Tech. Rep., 2016.

[2] G. J.W. van Bussel, A. R. Henderson, C. A. Morgan, S. Smith, R. Barthelmie, K. Argyriadis, A. Arena, G. Niklasson, and E. Peltola, "State of the Art and Technology Trends for Offshore Wind Energy : Operation and Maintenance Issues," in Offshore Wind Energy Special Topic, 2001.

[3] IRENA, "Renewable Energy Technologies: Cost Analysis Series," Tech. Rep. 5, 2012.

[4] P. Tavner, G. van Bussel, and F. Spinato, "Machine and converter reliabilities in wind turbines," in 3rd IET International Conference on Power Electronics, Machines and Drives (PEMD 2006). IEE, 2006.

[5] P. J. Tavner, J. Xiang, and F. Spinato, "Reliability Analysis for Wind Turbines,” Wind Energy, vol. 10, no. 1, pp. 1-18, Jan. 2007.

[6] J. Ribrant and L. M. Bertling, "Survey of Failures in Wind Power Systems With Focus on SwedishWind Power Plants During 19972005," IEEE Transactions on Energy Conversion, vol. 22, no. 1, pp. 167-173, Mar. 2007

[7] E. Echavarria, B. Hahn, G. J. W. van Bussel, and T. Tomiyama, "Reliability of Wind Turbine Technology Through Time," Journal of Solar Energy Engineering, vol. 130, no. 3, pp. 031 005-1 - 031 $005-8,2008$.

[8] F. Spinato, P. Tavner, G. van Bussel, and E. Koutoulakos, "Reliability of Wind Turbine Subassemblies," IET Renewable Power Generation, vol. 3, no. 4, pp. 387-401, 2009.

[9] S. Faulstich, B. Hahn, and P. J. Tavner, "Wind Turbine Downtime and its Importance for Offshore Deployment," Wind Energy, vol. 14, no. 3, pp. 327-337, Apr. 2011.

[10] P. Lyding, S. Faulstich, B. Hahn, and P. Tavner, "Reliability of the Electrical Parts of Wind Energy Systems - a Statistical Evaluation of Practical Experiences," in EPE Wind Energy Chapter Symposium, 2010.

[11] K. Alewine and W. Chen, "A Review of Electrical Winding Failures in Wind Turbine Generators," IEEE Electrical Insulation Magazine, vol. 28, no. 4, pp. 8-13, Jun. 2012.

[12] U. Shipurkar, K. Ma, H. Polinder, F. Blaabjerg, and J. A. Ferreira, "A Review of Failure Mechanisms in Wind Turbine Generator Systems," in 2015 17th European Conference on Power Electronics and Applications (EPE'15 ECCE-Europe). IEEE, Sep. 2015, pp. $1-10$.

[13] M. Ciappa, "Selected Failure Mechanisms of Modern Power 
Modules," Microelectronics Reliability, vol. 42, no. 4-5, pp. $653-$ 667, Apr. 2002.

[14] R.Wu, F. Blaabjerg, H.Wang, M. Liserre, and F. Iannuzzo, "Catastrophic Failure and Fault-Tolerant Design of IGBT Power Electronic Converters - an Overview," in IECON 2013 -39th Annual Conference of the IEEE Industrial Electronics Society. IEEE, Nov. 2013, pp. 507-513.

[15] G. Soelkner, W. Kaindl, H.-J. Schulze, and G. Wachutka, "Reliability of Power Electronic Devices Against Cosmic Radiation-induced Failure," Microelectronics Reliability, vol. 44, no. 9-11, pp. 13991406, Sep. 2004.

[16] J. Birk and B. Andresen, "Parallel-connected Converters for Optimizing Efficiency, Reliability and Grid Harmonics in a Wind Turbine," in 2007 European Conference on Power Electronics and Applications. IEEE, 2007, pp. 1-7.

[17] C. Delepaut, S. Siconolfi, O. Mourra, and F. Tonicello, "MOSFET Gate Open Failure Analysis in Power Electronics," in 2013 TwentyEighth Annual IEEE Applied Power Electronics Conference and Exposition (APEC). IEEE, Mar. 2013, pp. 189-196.

[18] M. Boettcher and F.W. Fuchs, "Power Electronic Converters inWind Energy Systems Considerations of Reliability and Strategies for Increasing Availability," in European Conference on Power Electronics and Applications, 2011, pp. 1-10.

[19] W. Lifeng, Z. Shihong, D. Yinyu, G. Yong, and P. Wei, "Research on Failure Analysis Method of the Key Components in SMPS," in 2011 Prognostics and System Health Managment Confernece. IEEE, May 2011, pp. 1-6.

[20] H. Wang and F. Blaabjerg, "Reliability of Capacitors for DC-Link Applications in Power Electronic Converters - An Overview," IEEE Transactions on Industry Applications, vol. 50, no. 5, pp. 35693578, Sep. 2014.

[21] R. Brutsch, M. Tari, K. Frohlich, T. Weiers, and R. Vogelsang, "Insulation Failure Mechanisms of Power Generators [Feature Article]," IEEE Electrical Insulation Magazine, vol. 24, no. 4, pp. 17-25, Jul. 2008.

[22] V. I. J. Kokko, "Ageing Due to Thermal Cycling by Start and Stop Cycles in Lifetime Estimation of Hydroelectric Generator Stator Windings," in 2011 IEEE International Electric Machines \& Drives Conference (IEMDC). IEEE, May 2011, pp. 318-323.

[23] "Ageing Due to Thermal Cycling by Power Regulation Cycles in Lifetime Estimation of Hydroelectric Generator Stator Windings," in 2012 XXth International Conference on Electrical Machines. IEEE, Sep. 2012, pp. 1559-1564.

[24] Weijun Yin, "Failure Mechanism ofWinding Insulations in Inverterfed Motors," IEEE Electrical Insulation Magazine, vol. 13, no. 6, pp. 18-23, Nov. 1997.

[25] G. Gao and W. Chen, "Design Challenges of Wind Turbine Generators," in 2009 IEEE Electrical Insulation Conference. IEEE, May 2009, pp. 146-152.

[26] R. Curiac and H. Li, "Improvements in Energy Efficiency of Induction Motors by the use of Magnetic Wedges," in 2011 Record of Conference Papers Industry Applications Society 58th Annual IEEE Petroleum and Chemical Industry Conference (PCIC). IEEE, Sep. 2011, pp. 1-6.

[27] A. Hamidi, N. Beck, K. Thomas, and E. Herr, "Reliability and Lifetime Evaluation of Different Wire Bonding Technologies for High Power IGBT Modules," Microelectronics Reliability, vol. 39, pp. 1153-1158, 1999.

[28] B. Baliga, "Package and Module Design," in The IGBT Device. Elsevier Ltd, 2015, p. 732.

[29] R. Bayerer, "Advanced Packaging Yields Higher Performance and Reliability in Power Electronics," Microelectronics Reliability, vol. 50, pp. 1715-1719, 2010.

[30] K. Guth, D. Siepe, J. Görlich, H. Torwesten, R. Roth, F. Hille, and F. Umbach, "New Assembly and Interconnects Beyond Sintering Methods," in International Conference on Power Conversion and Intelligent Motion (PCIM), 2010, pp. 219-224.

[31] R. Schmidt, U. Scheuermann, and E. Mike, "Al-clad Cu Wire Bonds Multiply Power Cycling Lifetime of Advanced Power Modules," in International Conference on Power Conversion and Intelligent Motion (PCIM), 2012.
[32] J. Ling, T. Xu, R. Chen, O. Valentin, and C. Luechinger, " $\mathrm{Cu}$ and $\mathrm{Al}-$ $\mathrm{Cu}$ composite-material interconnects for power devices," in 2012 IEEE 62nd Electronic Components and Technology Conference. IEEE, May 2012, pp. 1905-1911.

[33] Y. Fujii, Y. Ishikawa, S. Takeguchi, and J. Onuki, "Development of High-Reliability ThickAl-Mg2Si Wire Bonds for High-Power Modules," in International Symposium on PowerSemiconductor Devices and ICs, 2012, pp. 279-282.

[34] U. Geißler, J. Göhre, S. Thomas, M. Schneider-Ramelow, and K.D. Lang, "A new Aluminium Alloy for Heavy Wire Bonding in Power Electronics - First Tests of Bonding Behaviour and Reliability Specification of the AlX-alloy," in International Conference on Power Conversion and Intelligent Motion (PCIM), 2013, pp. 14-16.

[35] B. Ong, M. Helmy, S. Chuah, C. Luechinger, and G.Wong, "Heavy Al Ribbon Interconnect: An Alternative Solution for Hybrid Power Packaging," in IMAPS, 2004, pp. 1-11.

[36] S. Jacques, R. Leroy, and M. Lethiecq, "Impact of Aluminum Wire and Ribbon Bonding Technologies on D2PAK Package Reliability during Thermal Cycling Applications," Microelectronics Reliability, vol. 55, no. 9-10, pp. 1821-1825, Aug. 2015.

[37] T. Stockmeier, P. Beckedahl, C. Gobl, and T. Malzer, "SKiN: Double Side Sintering Technology for New Packages," in 2011 IEEE 23rd International Symposium on Power Semiconductor Devices and ICs. IEEE, May 2011, pp. 324-327.

[38] U. Scheuermann, "Reliability of Planar SKiN Interconnect Technology," in 7th International Conference on Integrated Power Electronics Systems (CIPS), 2012, pp. 464-471.

[39] Y. Wang, X. Dai, G. Liu, D. Li, and S. Jones, "An Overview of Advanced Power Semiconductor Packaging for Automotive System Packaging of Power Module," in 9th International Conference on Integrated Power Electronics Systems (CIPS 2016), 2016, pp. 1-6.

[40] R. Dudek, R. Doring, M. Hildebrandt, S. Rzepka, S. Stegmeier, S. Kiefl, V. Sommer, G. Mitic, and K. Weidner, "Analyses of Thermomechanical Reliability Issues for Power Modules Designed in Planar Technology," in 2016 17th International Conference on Thermal, Mechanical and Multi-Physics Simulation and Experiments in Microelectronics and Microsystems (EuroSimE). IEEE, Apr. 2016, pp. 1-8.

[41] N. Benavides, T. McCoy, and M. Chrin, "Reliability Improvements in Integrated Power Systems with Pressure-Contact Semiconductors," in Proc. ASNE, 2009.

[42] L. Tinschert, A. R. Å rdal, T. Poller, M. Bohlländer,M. Hernes, and J. Lutz, "Possible Failure Modes in Press-Pack IGBTs," Microelectronics Reliability, vol. 55, no. 6, pp. 903-911, 2015.

[43] U. Scheuermann, "Packaging and Reliability of Power Modules Principles, Achievements and Future Challenges General Design Principles of Power Modules," in International Conference on Power Conversion and Intelligent Motion (PCIM), 2015, pp. 35-50.

[44] A. Morozumi, K. Yamada, T. Miyasaka, S. Sumi, and Y. Seki, "Reliability of Power Cycling for IGBT Power Semiconductor Modules," IEEE Transactions on Industry Applications, vol. 39, no. 3, pp. 665-671, May 2003.

[45] K. Guth, N. Oeschler, L. B"ower, R. Speckels, G. Strotmann, N. Heuck, S. Krasel, and A. Ciliox, "New Assembly and Interconnect Technologies for Power Modules," in International Conferecne on Integrated Power Electronics Systems (CIPS), 2012, pp. 380-384.

[46] L. Jiang, T. G. Lei, K. D. T. Ngo, G.-Q. Lu, and S. Luo, "Evaluation of Thermal Cycling Reliability of Sintered Nanosilver Versus Soldered Joints by Curvature Measurement," IEEE Transactions on Components, Packaging and Manufacturing Technology, vol. 4, no. 5, pp. 751-761, May 2014.

[47] R. Dudek, R. Doring, S. Rzepka, C. Ehrhardt, M. Gunther, and M. Haag, "Electro-thermomechanical Analyses on Silver Sintered IGBTmodule Reliability in Power Cycling," in 2015 16th International Conference on Thermal, Mechanical and Multi-Physics Simulation and Experiments in Microelectronics and Microsystems. IEEE, Apr. 2015, pp. 1-8.

[48] F. Le Henaff, S. Azzopardi, E. Woirgard, T. Youssef, S. Bontemps, and J. Joguet, "Lifetime Evaluation of Nanoscale Silver Sintered Power Modules for Automotive Application Based on Experiments and Finite-Element Modeling," IEEE Transactions on Device and 
Materials Reliability, vol. 15, no. 3, pp. 326-334, Sep. 2015.

[49] V. R. Manikam and Kuan Yew Cheong, "Die Attach Materials for High Temperature Applications: A Review," IEEE Transactions on Components, Packaging and Manufacturing Technology, vol. 1, no. 4, pp. 457-478, Apr. 2011.

[50] T. Schutze, H. Berg, and M. Hierholzer, "Further Improvements in the Reliability of IGBT Modules," in Conference Record of 1998 IEEE Industry Applications Conference. Thirty- Third IAS Annual Meeting (Cat. No.98CH36242), vol. 2. IEEE, 1998, pp. 1022-1025.

[51] G. Coquery and L. R., "Failure Criteria for Long Term Accelerated Power Cycling Test Linked to Electrical Turn Off SOA on IGBT Module. A 4000 Hours Test on 1200A-3300V Module with AlSiC Base Plate," Microelectronics Reliability, vol. 40, pp. 1665-1670, 2000.

[52] U. Scheuermann, "Reliability Challenges of Automotive Power Electronics," Microelectronics Reliability, vol. 49, no. 9-11, pp. 1319-1325, Sep. 2009

[53] J. Schulz-Harder, "Efficient Cooling of Power Electronics," in 3rd International Conference on Power Electronics Systems and Applications (PESA 2009), 2009, pp. 1-4.

[54] R. Skuriat and C. M. Johnson, "Direct Substrate Cooling of Power Electronics," in 2008 5th International Conference on Integrated Power Systems (CIPS), 2008.

[55] R. W. Bonner, T. Desai, F. Gao, X. Tang, T. Palacios, S. Shin, and M. Kaviany, "Die Level Thermal Storage for Improved Cooling of Pulsed Devices," in 2011 27th Annual IEEE Semiconductor Thermal Measurement and Management Symposium. IEEE, Mar. 2011, pp. 193-197.

[56] U. Soupremanien, H. Szambolics, S. Quenard, P. Bouchut, M. Roumanie, R. Bottazzini, and N. Dunoyer, "Integration of Metallic Phase Change Material in Power Electronics," in 2016 15th IEEE Intersociety Conference on Thermal and Thermomechanical Phenomena in Electronic Systems (ITherm). IEEE, May 2016, pp. $125-133$

[57] C. Gillot, C. Schaeffer, C. Massit, and L. Meysenc, "Doublesided Cooling for High Power IGBT Modules using Flip Chip Technology," IEEE Transactions on Components and Packaging Technologies, vol. 24, no. 4, pp. 698-704, 2001.

[58] C. M. Johnson, C. Buttay, S. J. Rashid, F. Udrea, G. A. J. Amaratunga, P. Ireland, and R. K. Malhan, "Compact Double-Side Liquid-Impingement-Cooled Integrated Power Electronic Module," in Proceedings of the 19th International Symposium on Power Semiconductor Devices and IC's, vol. 3. IEEE, May 2007, pp. 53-56.

[59] H. Calleja, F. Chan, and I. Uribe, "Reliability-Oriented Assessment of a DC/DC Converter for Photovoltaic Applications," in 2007 IEEE Power Electronics Specialists Conference. IEEE, 2007, pp. 15221527.

[60] G. Petrone, G. Spagnuolo, R. Teodorescu, M. Veerachary, and M. Vitelli, "Reliability Issues in Photovoltaic Power Processing Systems," IEEE Transactions on Industrial Electronics, vol. 55, no. 7, pp. 2569-2580, Jul. 2008.

[61] F. Chan and H. Calleja, "Reliability Estimation of Three SinglePhase Topologies in Grid- Connected PV Systems," IEEE Transactions on Industrial Electronics, vol. 58, no. 7, pp. 26832689, Jul. 2011

[62] S. Gierschner and H.-G. Eckel, "Lifetime Estimation of the BIGT in ANPC Converter and T-Type Converter for Wind Energy Application," in 8th IET International Conference on Power Electronics, Machines and Drives (PEMD 2016). IET, 2016, pp. 1-6.

[63] K. Ma and F. Blaabjerg, "Multilevel Converters for $10 \mathrm{MW}$ Wind Turbines," in 14th European Conference on Power Electronics and Applications (EPE 2011), 2011, pp. 1-10.

[64] M. Morisse, A. Bartschat, J. Wenske, and A. Mertens, "Converter Lifetime Assessment for Doubly-Fed Induction Generators Considering Derating Control Strategies at Low Rotor Frequencies," Journal of Physics: Conference Series, vol. 753, pp. 1-10, Sep. 2016.

[65] J. Holtz and N. Oikonomou, "Synchronous Optimal Pulsewidth Modulation and Stator Flux Trajectory Control for Medium-Voltage Drives," IEEE Transactions on Industry Applications, vol. 43, no. 2, pp. 600-608, 2007.

[66] "Optimal Control of a Dual Three-Level Inverter System for Medium-Voltage Drives," IEEE Transactions on Industry Applications, vol. 46, no. 3, pp. 1034-1041, 2010.

[67] C. A. dos Santos and F. L. M. Antunes, "Losses Comparison Among Carrier-Based PWM Modulation Strategies in Three- Level NeutralPoint-Clamped Inverter Key words The Three-level NPC Inverter,' in International Conference on Renewable Energies abd Power Quality, vol. 1, no. 9, 2011, pp. 1035-1040.

[68] I. Josifovic, J. Popovic-Gerber, and J. Ferreira, "A PCB System Integration Concept for Power Electronics," in 2009 IEEE 6th International Power Electronics and Motion Control Conference, vol. 3. IEEE, May 2009, pp. 756-762.

[69] "Power Sandwich Industrial Drive with SiC JFETs," in 14th European Conference on Power Electronics and Applications (EPE 2011), 2011.

[70] C. Joseph, M. Zolghadri, A. Homaifar, F. Lee, and R. Lorenz, "Novel Thermal Based Current Sharing Control of Parallel Converters," in 2004 10th International Workshop on Computational Electronics. IEEE, 2004, pp. 647-653.

[71] C. Nesgaard and M. Andersen, "Optimized Load Sharing Control by means of Thermal Reliability Management," in IEEE Power Electronics Specialists Conference. IEEE, 2004, pp. 4901-4906.

[72] "Efficiency Improvement in Redundant Power Systems by means of Thermal Load Sharing," in IEEE Applied Power Electronics Conference and Exposition., vol. 1. IEEE, 2004, pp. 433-439.

[73] D. Zhou, F. Blaabjerg, M. Lau, and M. Tonnes, "Reactive Power Impact on Lifetime Prediction of two-level Wind Power Converter," in International Conference on Power Conversion and Intelligent Motion (PCIM), 2013, pp. 564-571.

[74] "Optimized Reactive Power Flow of DFIG Power Converters for Better Reliability Performance Considering Grid Codes," IEEE Transactions on Industrial Electronics, vol. 62, no. 3, pp. 15521562, Mar. 2015.

[75] Dao Zhou, F. Blaabjerg, M. Lau, and M. Tonnes, "Thermal Behavior Optimization in Multi- MWWind Power Converter by Reactive Power Circulation," IEEE Transactions on Industry Applications, vol. 50, no. 1, pp. 433-440, Jan. 2014

[76] K. Ma, M. Liserre, and F. Blaabjerg, "Reactive Power Influence on the Thermal Cycling of Multi-MW Wind Power Inverter," IEEE Transactions on Industry Applications, vol. 49, no. 2, pp. 922-930, Mar. 2013

[77] J. Lemmens, J. Driesen, and P. Vanassche, "Dynamic DC-link Voltage Adaptation for Thermal Management of Traction Drives," in 2013 IEEE Energy Conversion Congress and Exposition. IEEE, Sep. 2013, pp. 180-187.

[78] V. Blasko, R. Lukaszewski, and R. Sladky, "On line Thermal Model and Thermal Management Strategy of a Three Phase Voltage Source Inverter," in Conference Record of the 1999 IEEE Industry Applications Conference. Thirty-Forth IAS Annual Meeting (Cat. No.99CH36370), vol. 2. IEEE, 1999, pp. 1423-1431.

[79] J. Lemmens, J. Driesen, and P. Vanassche, "Thermal Management in Traction Applications as a Constraint Optimal Control Problem," in 2012 IEEE Vehicle Power and Propulsion Conference. IEEE, Oct. 2012, pp. 36-41.

[80] M. Weckert and J. Roth-Stielow, "Lifetime as a Control Variable in Power Electronic Systems," in 2010 Emobility - Electrical Power Train, no. 1. IEEE, Nov. 2010, pp. 1-6.

[81] "Chances and Limits of a Thermal Control for a Three-Phase Voltage Source Inverter in Traction Applications using Permanent Magnet Synchronous or Induction Machines," in 2011 13th European Conference on Power Electronics and Applications (EPE'11 ECCE Europe), 2011, pp. 1-10.

[82] Lixiang Wei, J. McGuire, and R. a. Lukaszewski, "Analysis of PWM Frequency Control to Improve the Lifetime of PWM Inverter," IEEE Transactions on Industry Applications, vol. 47, no. 2, pp. 922-929, Mar. 2011

[83] J. Falck, M. Andresen, and M. Liserre, "Active Thermal Control of IGBT Power Electronic Converters," in IECON 2015 - 41st Annual Conference of the IEEE Industrial Electronics Society. IEEE, Nov. 2015, pp. 000 001-000 006. 
[84] P. Hofer, N. Karrer, and C. Gerster, "Paralleling Intelligent IGBT Power Modules with Active Gate-controlled Current Balancing," in PESC Record. 27th Annual IEEE Power Electronics Specialists Conference, vol. 2. IEEE, 1996, pp. 1312-1316.

[85] X.Wang, Z. Zhao, and L. Yuan, "Current Sharing of IGBT Modules in Parallel with Thermal Imbalance," in 2010 IEEE Energy Conversion Congress and Exposition. IEEE, Sep. 2010, pp. 21012108.

[86] H. Luo, F. Iannuzzo, K. Ma, F. Blaabjerg, W. Li, and X. He, “Active Gate Driving Method for Reliability Improvement of IGBTs via Junction Temperature Swing Reduction," in 2016 IEEE 7th International Symposium on Power Electronics for Distributed Generation Systems (PEDG). IEEE, Jun. 2016, pp. 1-7.

[87] L. Wu and A. Castellazzi, "Temperature Adaptive Driving of Power Semiconductor Devices," in 2010 IEEE International Symposium on Industrial Electronics. IEEE, Jul. 2010, pp. 1110-1114.

[88] J. F. Wolfle and J. Roth-Stielow, "A Hybrid Discontinuous Modulation Technique to Influence the Switching Losses of Three Phase Inverters," in 2015 17th European Conference on Power Electronics and Applications (EPE'15 ECCE-Europe). IEEE, Sep. 2015, pp. 1-10.

[89] D. Kaczorowski, M. Mittelstedt, and A. Mertens, "Investigation of Discontinuous PWM as Additional Optimization Parameter in an Active Thermal Control," in 2016 18th European Conference on Power Electronics and Applications (EPE'16 ECCE Europe). IEEE, Sep. 2016, pp. 1-10.

[90] J. Wolfle, M. Nitzsche, J. Weimer, M. Stempfle, and J. Roth-Stielow, "Temperature Control System using a Hybrid Discontinuous Modulation Technique to Improve the Lifetime of IGBT Power Modules," in 2016 18th European Conference on Power Electronics and Applications (EPE'16 ECCE Europe). IEEE, Sep. 2016, pp. $1-10$.

[91] A. C. de Rijck and H. Huisman, "Power Semiconductor Device Adaptive Cooling Assembly," Patent WO/2010/041 175 A1, 2010.

[92] M. Foster, D. Stone, and J. Davidson, "Real-time Temperature Monitoring and Control for Power Electronic Systems under Variable Active Cooling by Characterisation of Device Thermal Transfer Impedance," in 7th IET International Conference on Power Electronics, Machines and Drives (PEMD 2014). Institution of Engineering and Technology, 2014, pp. 1-6.

[93] J. N. Davidson, D. A. Stone, M. P. Foster, and D. T. Gladwin, "Real-Time Temperature Estimation in a Multiple Device Power Electronics System Subject to Dynamic Cooling," IEEE Transactions on Power Electronics, vol. 31, no. 4, pp. 2709-2719, Apr. 2016.

[94] L. Hao, "Degradation-Based Control of Multi-Component Systems Degradation-Based Control of Multi-Component Systems," PhD diss., Georgia Institute of Technology, 2015.

[95] L. Hao, K. Liu, N. Gebraeel, and J. Shi, "Controlling the Residual Life Distribution of Parallel Unit Systems Through Workload Adjustment," IEEE Transactions on Automation Science and Engineering, pp. 1-11, 2015.

[96] U. Shipurkar, H. Polinder, and J. A. Ferreira, "Modularity in Wind Turbine Generator Systems Opportunities and Challenges," in European Conference on Power Electronics and Applications (EPE'16 ECCE Europe). IEEE, Sep. 2016, pp. 1-10.

[97] H. Polinder, H. Lendenmann, R. Chin, and W. Arshad, "Fault Tolerant Generator Systems for Wind Turbines," in 2009 IEEE International Electric Machines and Drives Conference. IEEE, May 2009, pp. 675-681.

[98] B. Welchko, T. Lipo, T. Jahns, and S. Schulz, "Fault Tolerant Threephase AC Motor Drive Topologies: a Comparison of Features, Cost, and Limitations," in IEEE International Electric Machines and Drives Conference, 2003. IEMDC'03., vol. 1, no. 4. IEEE, 2003, pp. 539-546.

[99] C.-C. Yeh and N. A. O. Demerdash, "Induction Motor-Drive Systems with Fault Tolerant Inverter-Motor Capabilities," in 2007 IEEE International Electric Machines \& Drives Conference, vol. 2. IEEE, May 2007, pp. 1451-1453.

[100] Zhou Junwei, Qiu Yingning, Feng Yanhui, and Feng Kai, "Fault Tolerance forWind Turbine Power Converter," in 2nd IET
Renewable Power Generation Conference (RPG 2013). IET, 2013, pp. 3.24-3.24

[101] A. Gaillard, S. Karimi, P. Poure, S. Saadate, and E. Gholipour, "A Fault Tolerant Converter Topology for Wind Energy Conversion System with Doubly Fed Induction Generator," in 2007 European Conference on Power Electronics and Applications. IEEE, 2007, pp. $1-6$

[102] A. Gaillard, P. Poure, and S. Saadate, "FPGA-based Reconfigurable Control for Switch Fault Tolerant Operation of WECS with DFIG without Redundancy," Renewable Energy, vol. 55, pp. 35-48, Jul. 2013.

[103] B. Andresen and J. Birk, "A High Power Density Converter System for the Gamesa G10x 4,5 MW Wind Turbine," in 2007 European Conference on Power Electronics and Applications. IEEE, 2007, pp. $1-8$

[104] T. Zhang and A. Zain, "Modular Converter System Reliability \& Performance Analysis in Design," in The 2nd International Symposium on Power Electronics for Distributed Generation Systems. IEEE, Jun. 2010, pp. 252-258.

[105] N. R. Brown, T. M. Jahns, and R. D. Lorenz, "Power Converter Design for an Integrated Modular Motor Drive," in 2007 IEEE Industry Applications Annual Meeting. IEEE, Sep. 2007, pp. 1322 1328.

[106] M. D. Hennen, M. Niessen, C. Heyers, H. J. Brauer, and R. W. De Doncker, "Development and Control of an Integrated and Distributed Inverter for a Fault Tolerant Five-Phase Switched Reluctance Traction Drive," IEEE Transactions on Power Electronics, vol. 27, no. 2, pp. 547-554, Feb. 2012.

[107] A. Shea and T. M. Jahns, "Hardware Integration for an Integrated Modular Motor Drive Including Distributed Control," in 2014 IEEE Energy Conversion Congress and Exposition (ECCE). IEEE, Sep. 2014, pp. 4881-4887.

[108] J. Wolmarans, M. Gerber, H. Polinder, S. de Haan, J. Ferreira, and D. Clarenbach, "A 50kW Integrated Fault Tolerant Permanent Magnet Machine and Motor Drive," in 2008 IEEE Power Electronics Specialists Conference. IEEE, Jun. 2008, pp. 345-351.

[109] M. Davis, "Problems and Solutions with Magnetic Stator Wedges," in IRIS Rotating Machine Conference, 2007.

[110] K. Alewine and C.Wilson, "MagneticWedge Failures inWind Turbine Generators," in 2013 IEEE Electrical Insulation Conference (EIC), no. June. IEEE, Jun. 2013, pp. 244-247.

[111] H. Polinder, F. Van Der Pijl, G.-J. De Vilder, and P. Tavner, "Comparison of Direct-Drive and Geared Generator Concepts for Wind Turbines," IEEE Transactions on Energy Conversion, vol. 21, no. 3, pp. 725-733, Sep. 2006.

[112] J. Carroll, A. McDonald, and D. McMillan, "Reliability Comparison ofWind TurbinesWith DFIG and PMG Drive Trains," IEEE Transactions on Energy Conversion, vol. 30, no. 2, pp. 663-670, Jun. 2015.

[113] R. McMahon, E. Abdi, P. Malliband, S. Shao, M. Mathekga, and P. Tavner, "Design and Testing of a $250 \mathrm{~kW}$ Medium-speed Brushless DFIG," in 6th IET International Conference on Power Electronics, Machines and Drives (PEMD 2012). IET, 2012, pp. D12-D12.

[114] T. D. Strous, U. Shipurkar, H. Polinder, and J. A. Ferreira, "Comparing the Brushless DFIM to other Generator Systems for Wind Turbine Drive-Trains," Journal of Physics: Conference Series, vol. 753, p. 112014, Sep. 2016.

[115] U. Shipurkar, T. D. Strous, H. Polinder, and J. A. Ferreira, "LVRT Performance of Brushless Doubly Fed Induction Machines A Comparison," in 2015 IEEE International Electric Machines \& Drives Conference (IEMDC), no. 6. IEEE, May 2015, pp. 362-368.

[116] H. Krupp and A. Mertens, "Rotary Transformer Design for Brushless Electrically Excited Synchronous Machines," in 2015 IEEE Vehicle Power and Propulsion Conference (VPPC). IEEE, Oct. 2015, pp. $1-6$

[117] S.-A. Vip, J.-N. Weber, A. Rehfeldt, and B. Ponick, "Rotary Transformer with Ferrite Core for Brushless Excitation of Synchronous Machines," in 2016 XXII International Conference on Electrical Machines (ICEM). IEEE, Sep. 2016, pp. 890-896.

[118] K. Sawa and E. I. Shobert, "Sliding Electrical Contacts (Graphitic Type Lubrication)," in Electrical Contacts: principles and 
applications, P. G. Slade, Ed. CRC Press, 2013, pp. 1042-1079.

[119] M. Braunovic, "Sliding Contacts," in Electrical Contacts: Fundamentals, Applications and Technology, M. Braunovic, N. K. Myshkin, and V. V. Konchits, Eds. CRC Press, 2006, pp. 369-494.

[120] M. van der Laan and H. J. Koelman, "Rotary Electrical Conductor," Patent WO/2016/032 336 A1, 2016.

[121] M. Botha, "Electrical Machine Failures, Causes and Cures," in Eighth International Conference on Electrical Machines and Drives, vol. 1997, no. 444. IEE, 1997, pp. 114-117.

[122] G. Stone, I. Culbert, E. Boulter, and H. Dhirani, Electrical Insulation for Rotating Machines: Design, Evaluation, Aging, Testing, and Repair, 2nd ed. Wiley-IEEE Press, 2014.

[123] M. Melfi, "Low-Voltage PWM Inverter-fed Motor Insulation Issues," IEEE Transactions on Industry Applications, vol. 42, no. 1, pp. 128-133, Jan. 2006

[124] H. W. Oh and A. Willwerth, "Shaft Grounding A Solution to Motor Bearing Currents," ASHRAE Transactions, vol. 114, 2008.

[125] R. Schiferl and M. Melfi, "Bearing Current Remediation Options," IEEE Industry Applications Magazine, vol. 10, no. 4, pp. 40-50, Jul. 2004.

[126] Fei Wang, "Motor Shaft Voltages and Bearing Currents and their Reduction in Multilevel Medium-voltage PWM Voltage-sourceinverter Drive Applications," IEEE Transactions on Industry Applications, vol. 36, no. 5, pp. 1336-1341, 2000.

[127] M. BeBortoli, S. Salon, D. Burow, and C. Slavik, "Effects of Rotor Eccentricity and Parallel Windings on Induction Machine Behavior: a Study Using Finite Element Analysis," IEEE Transactions on Magnetics, vol. 29, no. 2, pp. 1676-1682, Mar. 1993.

[128] A. Di Gerlando, G. M. Foglia, and R. Perini, "Analytical Modelling of Unbalanced Magnetic Pull in Isotropic Electrical Machines," in Proceedings of the 2008 International Conference on Electrical Machines, ICEM'08, 2008.

[129] D. G. Dorrell, J. K. H. Shek, M. A. Mueller, and M. F. Hsieh, "Damper Windings in Induction Machines for Reduction of Unbalanced Magnetic Pull and Bearing Wear," IEEE Transactions on Industry Applications, vol. 49, no. 5, pp. 2206-2216, 2013.

[130] Y. Jiang, "Wind Turbine Cooling Technologies," in Critical Infrastructure Security: Assessment, Prevention, Detection, Response, Jun. 2010, vol. 54, pp. 613-640.

[131] R. Gray, L. Montgomery, R. Nelson, J. Pipkin, S. Joki-Korpel, and F. Caguiat, "Designing the Cooling Systems for the World's Most Powerful Turbogenerator - Olkiluoto Unit 3," in IEEE Power Engineering Society General Meeting. IEEE, 2006, p. 5 pp.

[132] R. Scott Semken, M. Polikarpova, P. Roytta, J. Alexandrova, J. Pyrhonen, J. Nerg, A. Mikkola, and J. Backman, "Direct-drive Permanent Magnet Generators for High-power Wind Turbines: Benefits and Limiting Factors," IET Renewable Power Generation, vol. 6 , no. 1 , p. 1,2012

[133] J. Pyrhönen, J. Nerg, H. Jussila, Y. Alexandrova, M. Polikarpova, R. S. Semken, and P. Röyttä, "Stator of an Electrical Machine and an Electrical Machine," Patent US 20130285487 A1, 2013.

[134] J. Shek, D. Dorrell, M. Hsieh, D. Macpherson, and M. Mueller, "Reducing Bearing Wear in Induction Generators for Wave and Tidal Current Energy Devices," in IET Conference on Renewable Power Generation (RPG 2011), vol. 2011, no. 579 CP. IET, 2011, pp. P23P23.

[135] U. Ungku Amirulddin, G. Asher, P. Sewell, and K. Bradley, "Dynamic Field Modelling of Torque and Radial Forces in Vector-controlled Induction Machines with Bearing Relief," IEE Proceedings Electric Power Applications, vol. 152, no. 4, p. 894, 2005.

[136] M. Osama and T. A. Lipo, "A Magnetic Relief Scheme for Four Pole Induction Motors," in International Conference on Electrical Machines, Converters and Systems, 1999, pp. 115-121.

[137] T. Tera, Y. Yamauchi, A. Chiba, T. Fukao, and M. Rahman, "Performances of Bearingless and Sensorless Induction Motor Drive Based on Mutual Inductances and Rotor Displacements Estimation," IEEE Transactions on Industrial Electronics, vol. 53, no. 1, pp. 187-194, Feb. 2006.

[138] K. Raggl, B. Warberger, T. Nussbaumer, S. Burger, and J. Kolar, "Robust Angle-Sensorless Control of a PMSM Bearingless Pump," IEEE Transactions on Industrial Electronics, vol. 56, no. 6, pp.
2076-2085, Jun. 2009

[139] S. A. Niknam, "Prognostic-based Life Extension Methodology with Application to Power Generation Systems," PhD diss., University of Tennessee, 2014

[140] B. Mecrow, A. Jack, J. Haylock, and J. Coles, "Fault-tolerant Permanent Magnet Machine Drives," IEEE Proceedings - Electric Power Applications, vol. 143, no. 6, p. 437, 1996.

[141] C. Noel, N. Takorabet, and F. Meibody-Tabar, "Short-circuit Current Reduction Technique for Surface Mounted PM Machines High Torque-low Speed Applications," in Conference Record of the 2004 IEEE Industry Applications Conference, 2004. 39th IAS Annual Meeting., vol. 3. IEEE, 2004, pp. 1427-1433.

[142] B. Vaseghi, N. Takorabet, and F. Meibody-Tabar, "Short-circuit Current Reduction of PM Motors by Magnet Segmentation Technique," in 14th Biennial IEEE Conference on Electromagnetic Field Computation. IEEE, 2010, pp. 1-1.

[143] E. Spooner, A. C.Williamson, and G. Catto, "Modular Design of Permanent-magnet Generators for Wind Turbines," IEE Electrical Power Applications, vol. 143, no. 5, pp. 388-395, 1996.

[144] T. M. Jahns, "Improved Reliability in Solid-State AC Drives by Means of Multiple Independent Phase Drive Units," IEEE Transactions on Industry Applications, vol. IA-16, no. 3, pp. 321331, May 1980.

[145] D. Vizireanu, X. Kestelyn, S. Brisset, P. Brochet, Y. Milet, and D. Laloy, "Polyphased Modular Direct-drive Wind Turbine Generator," in 2005 European Conference on Power Electronics and Applications. IEEE, 2005, p. 9.

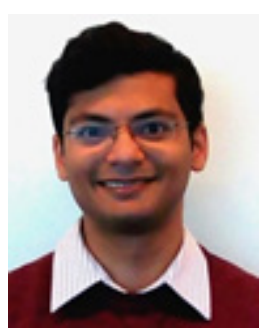

Udai Shipurkar received the M.Sc. degree in electrical engineering from Delft University of Technology, The Netherlands, in 2014, where he is currently working toward a Ph.D. degree. His current research focus is the design for reliable power production in wind turbine generator systems.

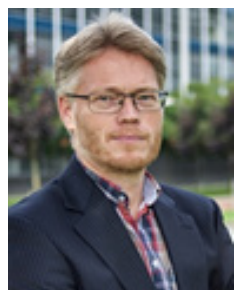

Henk Polinder obtained a Ph.D. from Delft University of Technology, the Netherlands. Since 1996, he has been an assistant/associate professor at Delft University of Technology in the field of electrical machines and drives. He worked part-time in industry, at the wind turbine manufacturer Lagerwey in 1998 and 1999, at Philips CFT in 2001 and at ABB Corporate Research in Vasteras in 2008. $\mathrm{He}$ was a visiting scholar at the University of Newcastle upon- Tyne in 2002, at Laval University in Quebec in 2004, at the University of Edinburgh in 2006 and at the University of Itajuba in 2014. He is author and co-author of over 250 publications. His main research interests are design aspects of electrical machines for application in electric mobility and renewable energy.

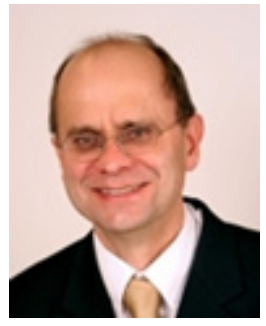

Jan A. Ferreira received the B.Sc.Eng., M Sc.Eng., and Ph.D. degrees in Electrical Engineering from the Rand Afrikaans University, Johannesburg, South Africa in 1981, 1983 and 1988 respectively. In 1981 he was with the Institute of Power Electronics and Electric Drives, Technical University of Aachen, and worked in industry at ESD (Pty) Ltd from 1982- 1985. From 1986 until 1997 he was at the Faculty of Engineering, Rand Afrikaans University, where he held the Carl and 
Emily Fuchs Chair of Power Electronics in later years. Since 1998 he is a professor at the Delft University of Technology in The Netherlands. Dr. Ferreira is a fellow of the IEEE. 